\title{
QUANTITATIVE EVALUATION OF MEDICAL RECORD DOCUMENTATION IN IMAM REZA HOSPITAL, MASHHAD, IRAN
}

\author{
Type of article: conference abstract
}

Zahra Mazloum khorasani1,Mahmood Tara2, Kobra Etminani3, zohre moosavi4,Zahra ebnehoseini5*

1: Assistant Professor of Endocrinology, Endocrine Research center, Mashhad University of Medical Sciences, Mashhad, Iran.

2: Ph.D. in Health Information Management, Assistant Professor, Department of Medical Records and Health Information Technology, School of Paramedical Sciences, Mashhad University of Medical Sciences, Mashhad, Iran.

3: Ph.D. in Health Information Management, Assistant Professor, Department of Medical Records and Health Information Technology, School of Paramedical Sciences, Mashhad University of Medical Sciences, Mashhad, Iran.

4: Associate Professor of Endocrinology, Endocrine Research center, Mashhad University of Medical Sciences, Mashhad, Iran.

5: Ph.D. Student Medical Informatics, Department of Medical Informatics, School of Medical, University of Medical Sciences, Mashhad, Iran.

* Tel: +98.09370802011, E-mail: EbnehoseiniZ1@Mums.ac.ir

\begin{abstract}
Introduction: Diabetes is the most common endocrine disease. Given the importance of medical record documentation for diabetic patients and its significant impact on accurate treatment process, as well as early diagnosis and treatment of acute and chronic complications, this study aimed to qualitatively evaluate medical record documentation of diabetic patients.

Methods:This descriptive and cross-sectional study was conducted on all medical records of diabetic patients (1200 cases) in the comprehensive Diabetes Center of Imam Reza Hospital. A checklist was prepared according to the main sectors and their sub-data elements to conduct a qualitative evaluation on documentation of medical records of diabetic patients. Descriptive statistics were used to report the results.

Results: In this study, 1200 ( 710 women and 490 men) cases were evaluated. Mean documentation of main sectors of diabetic patients' records were as follows: $49 \%$ demographic characteristics, $14 \%$ patient referral, $4 \%$ diagnosis, $50 \%$ lab tests, $25 \%$ diabetes medications, $13 \%$ nephropathy screening test, $10 \%$ diabetic neuropathy, $41 \%$ specialty and subspecialty consultations and internal medicine physicians visits did not completed for all the patients.

Conclusion:According to the results of this study, qualitative evaluation of medical record documentation of diabetic patients Showed poor documentation in this regard. It is suggested that results of this study be accessible to physicians of healthcare centers to take a positive step toward improved documentation of medical records. In addition, it seems necessary to modify diabetic medical records.
\end{abstract}

KEYWORDS: documentation, medical record

\section{Declaration of conflicts}

This abstract is selected from the First International Congress of Diseases and Health Outcomes Registry and First National Congress of Medical Informatics, 14-17 February 2017, Mashhad, Iran

\section{Authors' biography}

No biography. 
Medical Technologies Journal, Volume: 1, Issue: 4, October-December 2017, Pages:76-136. Doi : https://doi.org/10.26415/2572-004X-vol1iss4

\section{References}

No references. 